\title{
Lição de Anatomia
}

\author{
João Luiz Leocadio da Nova ${ }^{1}$ \\ José Joffily Bezerra Filho \\ Liana Albernaz de Melo Bastos ${ }^{3}$
}

DA NOVA, J.L.L., BEZERRA FILHO, J.J., BASTOS, L.A.M. An Anatomy lesson, Interface _ Comunicação, Saúde, Educação, v.4 , n.6, 2000.

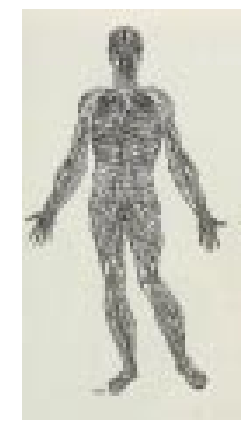

In medical education, we are currently witnessing the breakdown of both the teaching and the care models. There are many symptoms that reveal this phenomenon, including the ideology of coldness and the distance that pervades medical practice. This model of the patient-physician relationship reproduces the student-cadaver relation. With a view to modifying this ideology, we have developed an interdisciplinary activity at UFRJ (the Federal University of Rio de Janeiro), in conjunction with the Anatomy course, consisting of reflection groups with first year medical students. Based on the results attained over two years through this research project, called "The Cadaver and Medical Education", we produced a teaching video, "Anatomy Lesson", with the support of FUJB (José Bonifácio Foundation). This was the result of a multidisciplinary team effort, which included both teachers and students from the UFF Institute of Arts and Social Communication, the UFRJ Medical School and the NUTES (Educational Technology Center for Healthcare) of the UFRJ. It is our intention that this visual aid be used as a tool to help improve teaching and medical practice, by introducing a discussion of ethical issues. The research and process of producing the video revealed the possibility of rethinking and innovating in university education and proved to be, for all of us, a lesson on how to work together democratically.

KEYWORDS: medical education; anatomy; attitude to death; audiovisual aids.

$\mathrm{Na}$ formação médica, diagnosticamos a falência do modelo pedagógico/assistencial que se revela, dentre outros sintomas, na ideologia de frieza e distanciamento que perpassa a prática médica. Este modelo de relação médico-paciente reproduziria a relação estudante-cadáver. Visando modificar tal ideologia, desenvolvemos, na UFRJ, em atividade interdisciplinar com a Anatomia, grupos de reflexão com os alunos do primeiro período da Faculdade de Medicina. A partir dos resultados, de dois anos dessa pesquisa, denominada "O cadáver e a formação médica", realizamos, com o apoio da Fundação José Bonifácio, um vídeo didático, "Lição de Anatomia", por meio de equipe multidisciplinar, incluindo professores e alunos do Instituto de Artes e Comunicação Social da UFF, da Faculdade de Medicina da UFRJ e do Núcleo de Tecnologia Educacional para a Saúde da UFRJ (NUTES). Pretendemos que a utilização desse recurso audiovisual constitua mais uma ferramenta para a melhoria do ensino e da prática médica, introduzindo a discussão de questões éticas. A pesquisa e a realização do vídeo nos mostraram a possibilidade de se repensar e inovar o ensino universitário, o que foi, para todos nós, uma lição de convívio democrático.

PALAVRAS-CHAVE: educação médica; anatomia; atitude frente a morte; recursos audiovisuais.

\footnotetext{
${ }^{1}$ Professor da Universidade Federal Fluminense, chefe do Laboratório de Vídeo Educativo do Núcleo de Tecnologia Educacional para a Saúde da Universidade Federal do Rio de Janeiro.

${ }^{2}$ Professor do Laboratório de Roteiro do Departamento de Cinema e Vídeo do Instituto de Artes e Comunicação Social da Universidade Federal Fluminense.

${ }^{3}$ Professora da Faculdade de Medicina da Universidade Federal do Rio de Janeiro; coordenadora da pesquisa "O cadáver e a formação médica". E-mail: lianabastos@ax.apc.org
} 


\section{As origens}

A prática pedagógica da Psicologia Médica com os estudantes de Medicina do quarto, quinto e sexto períodos, da Universidade Federal do Rio de Janeiro UFRJ, tem-se centrado nas dificuldades encontradas no campo da relação médico-paciente. Esta ênfase deve-se ao diagnóstico de que o distanciamento $e$ a frieza com que a prática médica vem sendo exercida - e não apenas em nosso meio - são sintomas de um mal maior: as instituições de ensino médico têm informado o estudante, mas não o têm formado. A formação médica resume-se à transmissão de conhecimentos sobre as doenças. Valores $e$ atitudes de reconhecimento das subjetividades (tanto do médico quanto do paciente) não são privilegiados nesse modelo. Esta constatação levou-nos a pesquisar em que momento as escolas médicas iniciariam a produção dessa ideologia. Nossa hipótese inicial era a de que o embrião dela estaria no impacto que a prática anatômica provoca no estudante. A negação da mortalidade e da sexualidade humanas começaria a ser gerada na relação estudante-cadáver transferindo-se, posteriormente, para a relação médicopaciente. A revisão bibliográfica confirmou nossa hipótese. Iniciamos, junto à disciplina de Anatomia e com a colaboração de alguns de seus professores, um trabalho de campo que se desenvolveu por dois anos, sob a forma de grupos de reflexão com os estudantes do primeiro período da Faculdade de Medicina da UFRJ. Ao final desta etapa da pesquisa realizamos, com o apoio da Fundação Universitária José Bonifácio, um vídeo didático em atividade transdisciplinar com alunos de graduação e pós-graduação e professores da Faculdade de Medicina e do Núcleo de Tecnologia Educacional de Ciências da Saúde da UFRJ e do Curso de Cinema e Vídeo do Instituto de Artes Cênicas da Universidade Federal Fluminense (UFF).

O estudante e o cadáver

A prática anatômica é, para o estudante de medicina, um ritual de iniciação. É ali, diante do cadáver, que ele, no dizer das palavras de um estudante, "começa a se sentir médico". O cadáver é, assim, o primeiro paciente do futuro médico. O modo pelo qual o estudante lida com esta situação tem fundamental importância na formação de sua identidade profissional.

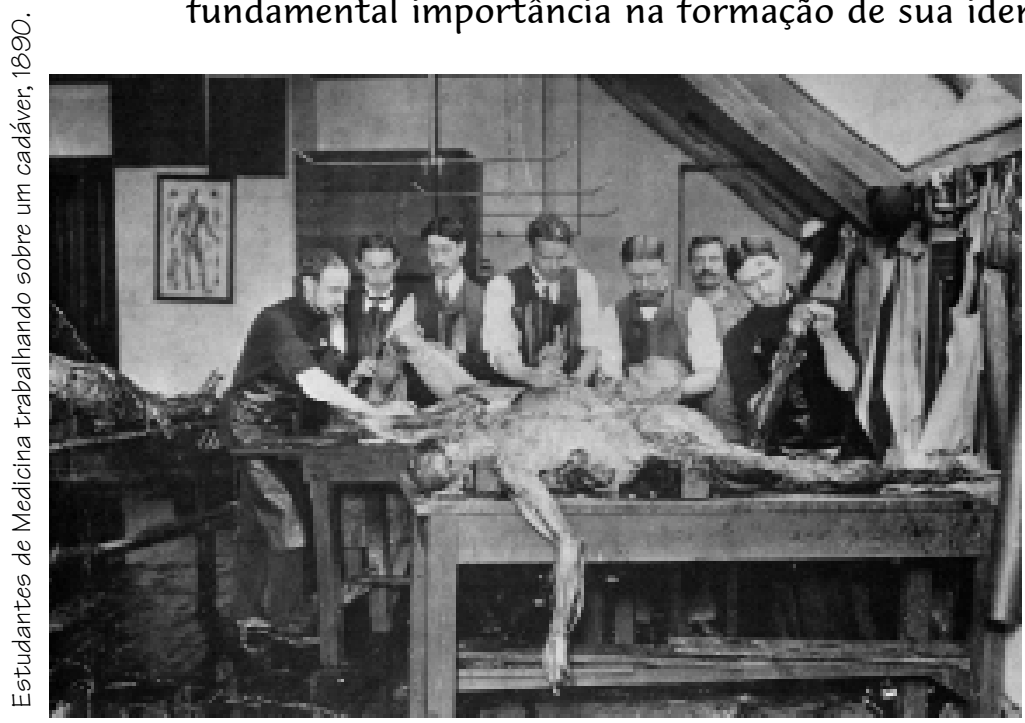

(Charlton et al.,1994)

Se, por um lado, diante do cadáver, o estudante se sente protegido das angústias que a prática com doentes suscita, por outro, ele é exposto, sem qualquer preparação, à enorme angústia que a morte promove. O estudante é apresentado à morte sem que o nome dela 
seja declinado.

O cadáver apresenta a morte, mas não é um morto. Ele é o corpo anatômico: um constructo, objeto de um discurso científico criado mediante uma técnica, a dissecção. O que a técnica anatômica pretende é, diante de um substrato dado, orientar-se num espaço já constituído,

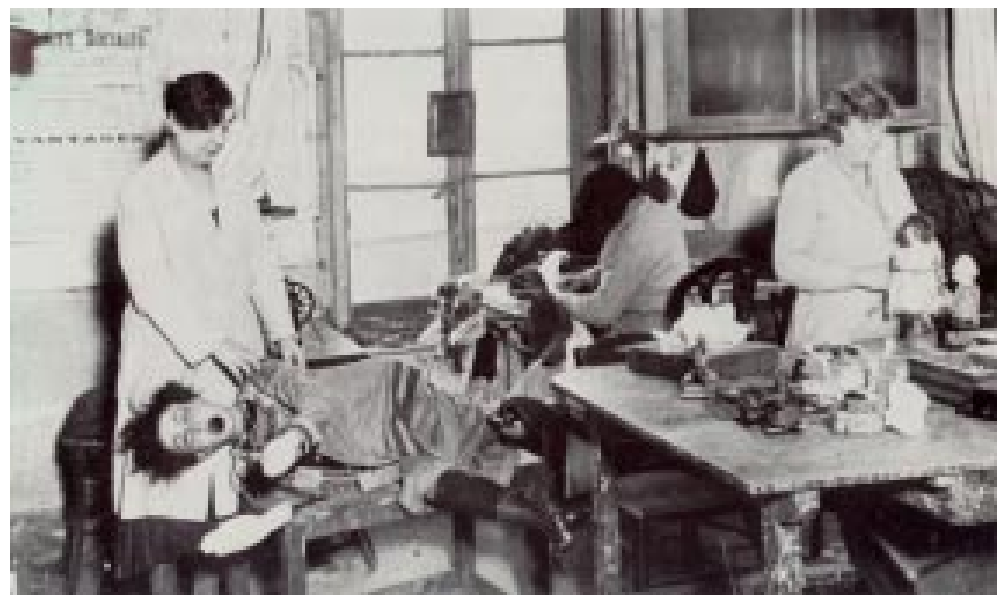

Fabricação de um autômato torná-lo visível e explorá-

lo geograficamente. Prática investigatória e não clínica, a dissecção não trata do doente e da doença. Ela trata do cadáver como uma figura exterior e objetiva (Foucault, 1987). Assim, o corpo anatômico é geografia, não é história. Deste modo, quando tomado como modelo para a relação médicopaciente, cria uma primeira cisão: o paciente é algo a ser visto e não ouvido. A dimensão histórica se achata neste encontro. As anamneses se fazem quase dispensáveis.

Perdendo a dimensão histórica, o que se perde é a vida e a sexualidade. $\mathrm{O}$ corpo morto, mobilizador de curiosidades e angústias, exige, daquele que o observa, neutralidade para vencer a náusea, o horror e a repugnância (Fèdida, 1971). Uma das técnicas utilizadas na busca da neutralidade necessária é a do silêncio.

A nomeação da morte raramente é feita diante do cadáver. Esta escotomização da morte - que se inicia diante do cadáver- prossegue durante todo o curso médico. O impacto que o contato com o cadáver produz no estudante não tem sido objeto de consideração na formação médica. Disto não se fala. Este modo de se negar a morte se desdobra numa posterior negação do morrer. A morte e o morrer não fazem parte do currículo acadêmico, mas são cotidianos na prática médica.

\section{$\mathrm{O}$ médico e a morte}

Morre-se hoje nos hospitais. A morte se transformou, em nossa cultura, num problema médico. Nem sempre foi assim. Esta parece ser uma modalidade dos nossos tempos que satisfaz à dessacralização e à banalização da morte cujas conseqüências não são inócuas. Os ritos de morte são cada vez mais simplificados. As conveniências exigem que o enlutado volte logo a uma vida normal. O recalcamento da dor é exigido em lugar das manifestações outrora usuais (Maunnoni, 1995). Freqüentemente, o profissional médico é solicitado a medicar aqueles que estão sofrendo com a perda de um ente querido. O luto se medicaliza.

Dentro do hospital, o moribundo - e, muitas vezes, a família - não tem participação na decisão da morte. Ela é uma "morte interdita" (Ariès, 1977). 


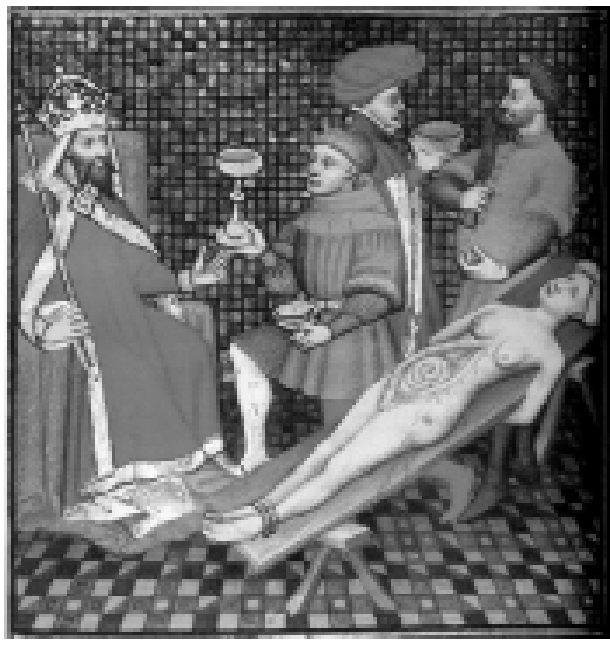

AGRIPINO BOCACCIO,

Nero assistindo à autópsia de sua mãe, 1410.

O médico foi colocado no lugar daquele que decide

o momento da morte e as circunstâncias do morrer. A morte e o morrer transformaram-se em questões técnicas. Neste contexto, criou-se uma ideologia médica de distanciamento e frieza desumanizadora tanto do paciente quanto do médico. Gerou-se um modelo de alienação de si $e$ do outro tornando o médico indiferente ao sofrimento $e$ às misérias humanas, exigindo um recalcamento da dor e uma negação da morte do outro e de si mesmo.

A formação médica, como não podia deixar de ser, promoveu e incorporou este modelo que condena à morte aquilo que o estudante tem de humanidade. Mata-se, no aluno, sua capacidade de envolvimento emocional com o paciente visandose, assim, supostamente, habilitá-lo a lidar com a morte (Zaidhaft, 1990). Cria-se um paradoxo: quanto mais a morte se torna "médica" menos dela se trata na formação. Mais interdita ela se faz não apenas para o moribundo mas, também, para o médico.

\section{O cadáver e a formação médica}

Com estas preocupações, coordenamos, há dois anos, uma pesquisa denominada "O cadáver e a formação médica", em atividade interdisciplinar com a Anatomia, realizando grupos de reflexão com os alunos do primeiro período da Faculdade de Medicina da UFRJ.

Focalizando a discussão de valores e atitudes analisados dentro de uma abordagem qualitativa, determinamos as categorias analíticas que nortearam a pesquisa: a cisão sujeito-objeto, operada na prática médica; a representação do ensino médico como o estudo das doenças; a divisão da formação médica em dois ciclos estanques (básico e profissional); a Anatomia, como iniciadora do estudo médico do corpo, tomando-se o cadáver como modelo; a relação médico-paciente fundada na relação estudante-cadáver.

Essas categorias empíricas foram identificadas por meio da escuta realizada pelos coordenadores dos grupos de reflexão - dois professores de Psicologia Médica da UFRJ com formação psicanalítica - tendo a Psicanálise como referencial teórico. Além destes, os grupos contavam com a colaboração de dois professores da Anatomia que funcionavam como observadores participantes. Tomamos o discurso livre do grupo como o conteúdo manifesto que pode ser interpretado, possibilitando a efetivação de mudanças na rede de relações simbólicas e materiais, produzindo novas significações pela confrontação dos valores sócio-ideológicos dos diferentes membros do grupo, mobilizados pelo contato com o cadáver. A desconstrução de modelos enrijecedores e impossibilitadores da emergência de novos sentidos fez-se pela leitura interpretativa da fala dos membros do 
grupo (Souza, 1989). Do material discursivo, foram isoladas as categorias empíricas que nos serviram para a verificação das hipóteses ou instalação de novas questões, comparando-as com as categorias analíticas propostas.

A utilização de um referencial teórico psicanalítico impôs-se pela própria metodologia proposta e sustentada na qualificação dos professores da Psicologia Médica envolvidos na pesquisa de campo (ambas com formação psicanalítica). Esta dupla identidade dos professores de Psicologia Médica não nos fez perder de vista a proposta pedagógica. Ter a psicanálise como referencial teórico, numa pesquisa de ensino médico, significou introduzir a subjetividade de onde ela foi oficialmente banida em nome de uma cosmovisão privilegiadora da objetividade que entrou em crise. Se nosso problema implicava rediscutir as relações sujeito-objeto, o referencial psicanalítico pôde nos prover de elementos substantivos, mantendo em mente a formação médica. A Psicanálise tem legitimidade para ocupar um lugar dentro de um ensino de medicina que busca a humanização.

O trabalho com grupos de alunos não configurou uma psicoterapia, o que seria abusivo e impróprio no contexto pedagógico. Pela metodologia proposta e com o referencial teórico psicanalítico, visamos à escuta e à ressignificação do discurso dos alunos para uma efetiva mudança. Isto requer que a subjetividade da fala tenha um espaço de reconhecimento.

A revisão da literatura médica publicada nos últimos vinte anos (1976-1996), sobre o impacto

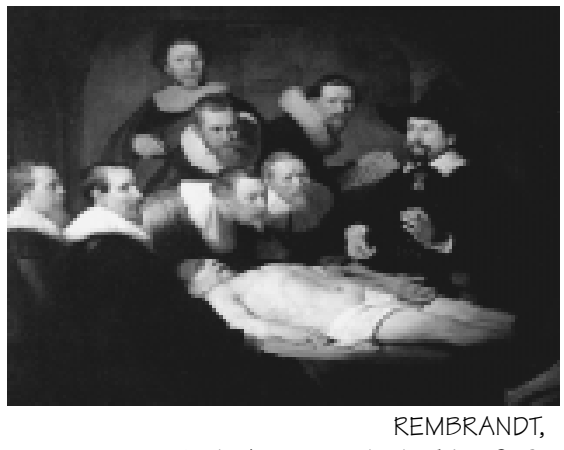
Lição de Anatomia do dr. Tulp, 1632. que o cadáver produz na formação médica, revela poucos trabalhos relativos ao tema.

Charlton et al. (1994), Alexander \& Haldane (1979), Blackwell et al. (1979), Gustavson (1988), Horne et al. (1990), Marks (1980), apontam para a importância que o encontro com o cadáver representa para o estudante de medicina na sua formação e posterior exercício profissional. Indicam que os mecanismos de defesa usados pelos estudantes diante da dissecção visa reduzir o estresse gerado pela situação, produzindo um modelo de distanciamento que se repete, posteriormente, na prática clínica, levando o médico a perceber seus pacientes não como seres humanos em sofrimento, mas como abstrações. Se o estudante tiver a chance de expressar suas preocupações e emoções, evocadas durante a dissecção do cadáver, isto possibilitará a ele empatizar com os pacientes. Sugerem que isto poderia ser conseguido pelo contato regular de pequenos grupos com facilitadores, seguindo sugestões de outros autores (Gustavson, 1988; Charlton et al., 1994). Os estudantes deveriam ser encorajados a examinar suas atitudes diante da morte e a aprender a lidar com o cadáver como um referente pessoal. Relatam achados de que 5\% dos estudantes informam distúrbios como pesadelos e elevado estresse, como resultado da dissecção de cadáveres. Concluem que a morte e o morrer deveriam ser incluídos nos currículos médicos, possibilitando aos estudantes tornarem-se, posteriormente, médicos com compaixão e sensibilidade, propondo, para 
isto, modificações curriculares (Penney, 1983).

Dissecar um cadáver não é um exercício técnico e neutro. O impacto que o cadáver produz permite a discussão de temas difíceis como dignidade humana, sexualidade, mortalidade e luto, trazendo à baila questões éticas.

o vídeo

Trabalhar com a imagem é fundamental dentro das modernas concepções pedagógicas, sendo particularmente importante na Medicina: o corpo como um dado a se ver. Mas não apenas isto. A proposta de realização do vídeo "O cadáver e a formação médica", ao término da pesquisa, visou transformar as categorias analíticas que a pesquisa apresentara em imagens, tornando imagístico o subjetivo. Além disso, um vídeo permitiria a ampliação de nosso público: atingiríamos não somente os alunos do primeiro período da Medicina, mas os dos períodos subseqüentes, criando-se uma possibilidade de multiplicação do questionamento ao longo do curso médico. Poderia ser utilizado, também, para treinamento de professores de Medicina e em outras áreas da saúde.

Não imaginávamos, no entanto, a incrível oportunidade de ensino e aprendizagem que a realização do vídeo trouxe para todos aqueles que dela participaram. Sua realização, inicialmente solicitada ao Laboratório de Vídeo Educativo do NUTES da UFRJ, construiu uma transdisciplinaridade que envolveu professores de duas universidades públicas (UFRJ e UFF), de diferentes áreas (Psicologia Médica, Anatomia, Clínica Médica, Tecnologia Educacional, Artes e Comunicação Social), alunos das graduações em Medicina ( UFRJ) e em Cinema e Vídeo (UFF) e alunos da pós-graduação (Mestrado em Tecnologia Educacional nas Ciências da Saúde da UFRJ). Desde a criação do roteiro até a avaliação do vídeo, todos pudemos aprender e ensinar. Os questionamentos que imaginávamos produzir em nosso público alvo se produziram dentro de nós, criando um espaço de interlocução, de reflexão e de ação.

Tanto para os seis alunos da UFF que escreveram, dirigiram e editaram o vídeo, como para os professores que se envolveram na orientação $e$ coordenação destas atividades, a realização do trabalho teve o sabor de uma experiência nova.

Os alunos, matriculados no segundo ou terceiro períodos do Departamento de Cinema e Vídeo da UFF, cursavam ali a cadeira optativa de Laboratório de Roteiro. Desde o momento da matricula foram informados sobre a proposta de integração entre alunos e professores das duas Universidades visando a produção de um vídeo. A maioria dos projetos desenvolvidos pelos alunos do Departamento de Cinema e Vídeo era de tema livre. Ou seja, os filmes e vídeos produzidos tinham geralmente, como argumento, temas de livre escolha dos próprios alunos. No caso desta proposta, o argumento era outro: “encomenda”. E não só isso, o vídeo resultante do trabalho teria uma platéia específica: alunos e professores de Faculdades de Medicina, bem como outros profissionais da área da saúde. $\mathrm{O}$ que, de início, parecia restritivo, funcionou como estímulo. O conteúdo do argumento foi transmitido pela Disciplina de Psicologia Médica da Faculdade 
de Medicina da UFRJ em diversos encontros com os alunos, coordenados pelo NUTES e pelo professor da disciplina de Laboratório de Roteiro. Também fazendo parte do aprendizado, os alunos da UFF visitaram, algumas vezes, o Laboratório Anatômico da UFRJ e assistiram a um dos grupos de reflexão com os estudantes de Medicina do primeiro período, coordenado pela professora de Psicologia Médica e com a participação de um professor de Anatomia.

\section{Ficção ou documentário?}

Depois de absorvidos os conceitos, surgiu a questão do gênero. De que forma abordar o assunto com mais eficiência? Através de uma história ficcionada ou de um documentário? Sob o ponto de vista dos alunos do Curso de Cinema, sem dúvida, a produção de imagens ficcionais formalizaria um exercício mais completo, tanto na escritura do roteiro quanto na confecção das imagens. A produção de imagens ficcionais envolve decisões mais variadas, que vão da cenografia à direção de atores. Chegou-se à conclusão que, também sob o ponto de vista do conteúdo, os conceitos originalmente discutidos seriam mais facilmente compreendidos. Faltava decidir qual o argumento que seria roteirizado. Foram desenvolvidos seis argumentos com os mesmos conceitos e em seguida foi escolhido um deles. Se a redação dos argumentos foi individual, a criação do roteiro foi coletiva. Foram escritas várias versões, mas o assunto central continuava sempre o mesmo: a formação médica. As consecutivas versões foram submetidas à avaliação dos professores diretamente envolvidos na sua realização (Psicologia Médica, Laboratório de Roteiro e NUTES), seguindo-se uma avaliação externa, com a participação de alunos e professores de Medicina.

\section{Avaliação do roteiro}

A fase de avaliação do roteiro, conduzida por um grupo de alunas do mestrado do NUTES, baseou-se numa leitura dramatizada do mesmo. Foram organizados dois grupos: um com professores de Medicina e outro com estudantes de Medicina. Em ambas as situações, procurou-se estimular os participantes a tecer comentários, livremente, sobre a credibilidade das situações propostas bem como sobre todo o desenrolar da narrativa. A análise desses grupos de discussão (Almenara, 1998) proporcionou novas mudanças no roteiro, na perspectiva do público-alvo que, até então, não havia se envolvido diretamente na produção.

A alternativa ficcional do roteiro permitiu que fossem discutidos desde as cenas que constituíam a história até os perfis profissionais e psicológicos de todos os personagens. Com esta técnica procurou-se descobrir não só o que é dito, mas também o que está por trás do que é dito. Finalmente, aprovada a versão final, o Laboratório de Vídeo Educativo do NUTES marcou o início das gravações. 


\section{Realizando o vídeo}

Os seis alunos de Laboratório de Roteiro, responsáveis pela redação do texto final, dividiram a direção do vídeo e também foram responsáveis por outras áreas ligadas à produção. A equipe, formada por técnicos do Laboratório de Vídeo Educativo do NUTES e alunos da UFF, dispôs de três dias para gravar as cenas. Para os alunos da UFF, a participação dos profissionais do NUTES foi de fundamental importância, pois a responsabilidade na execução do vídeo foi dividida com profissionais que têm mais de vinte anos de experiência.

Depois de uma meticulosa análise técnica do roteiro, a pré-produção, finalizada em cerca de 15 dias, viabilizou que as gravações fossem efetivadas no prazo previsto. Desde a seleção dos atores e dos figurinos até a escolha dos equipamentos e das locações, todas as decisões foram tomadas em conjunto. Esta construção coletiva é um espaço privilegiado como ambiente de aprendizagem, proposta que procuramos desenvolver em qualquer produção.

A fase de edição deste vídeo foi outra oportunidade didática aproveitada com a participação de mais duas outras alunas do Curso de Cinema da UFF. Este processo, tradicionalmente executado em ambiente de edição analógico e seqüencial, foi, pela primeira vez no NUTES, executado em ambiente digital de edição não linear. A edição digital possibilita que, durante a montagem, se escolha o ponto de corte de cada plano,intensificando-se o clima de tensão de uma discussão ao precipitarmos uma fala sobre a outra. Pode-se selecionar instantes centesimais. A inclusão de um plano de observação ou de reação sem fala de um dos atores auxilia a definir o personagem por ele representado. Muitas vezes é na reação sem fala que se configura a contrariedade de opiniões. O estudo das múltiplas opções de ordenação dos planos de imagem e som permite construir personagens e cenas de acordo com a intenção do roteiro. A experimentação das alternativas de seqüenciação dos planos pode ser feita à exaustão. Por serem arquivos digitais, virtuais, não há deterioração do material original, nem tampouco limitação quanto ao número de experimentações. Todas as alternativas podem ser analisadas simultaneamente, o que muito se assemelha à editoração de texto em que os familiares softwares de desktop publishing nos auxiliam a cortar, corrigir e manter diversas versões de relatórios, artigos, teses etc.

$\mathrm{O}$ vídeo, inicialmente programado pelos alunos-diretores para ter 72 planos de imagem, chegou a sua versão final com 92 planos. Acrescidos dos recursos de sonorização e de inclusão dos créditos e efeitos, compôs um programa com 16 minutos de duração.

Avaliado pelo público-alvo dentro de uma abordagem quali-quantitativa $e$ considerando-se os aspectos técnicos, estéticos e de pertinência do conteúdo, o vídeo recebeu dos alunos nota final seis, numa escala de um a sete, considerando os aspectos técnicos, estéticos e de pertinência do conteúdo analisados por eles. 


\section{Lição de Anatomia}

Lição de anatomia pretende um saber sobre seu objeto, mas o objeto da nossa lição não é, tão somente, o cadáver. O cadáver nos permitiu, pela pesquisa, traçar uma nova técnica. Nosso constructo não foi delimitado pela dissecção. Nossa técnica fundou-se na reflexão que o cadáver nos permite pelo impacto que a morte $e$ a sexualidade promovem em todos nós e, particularmente, no estudante de Medicina. Nosso constructo foi o campo da relação estudante-cadáver, desdobrando-se na relação médico-paciente. Pretendíamos apontar as vicissitudes da prática médica, discutindo as questões éticas e propondo mudanças na formação médica. Esses foram os objetivos do vídeo. Tal como o paciente, o vídeo é para ser visto e ouvido. Por isto não apresentamos aqui sua sinopse. Desejamos que ele possa ser assistido e utilizado. O objetivo deste texto é outro. É contar como a realização de vídeo se desdobrou em outra lição de capital importância.

A "Lição de Anatomia" nos colocou a todos, alunos e professores de Medicina, de Cinema e de Educação, diante de situações novas, de outras áreas do conhecimento, de diferentes modos de sentir, pensar e agir. Apontando para nossas insuficiências e desconhecimentos, ao mesmo tempo que nos fazendo sentir a necessidade que temos uns dos outros na complementariedade de nossos papéis e saberes, a realização do vídeo foi, ela própria, uma lição. Lição ética de um convívio democrático.

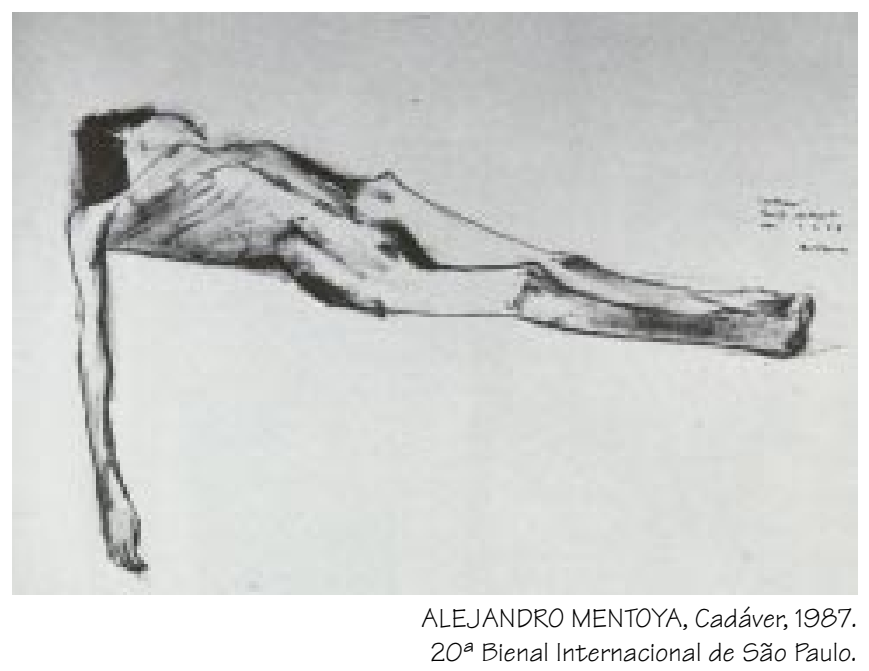




\section{Referências bibliográficas}

ALEXANDER, D. A., HALDANE, J.D. Medical education: a student perspective. Med. Educ., v.18, p.336-41, 1979.

ALMENARA, J.C. Avaliar para melhorar: meios e materiais de ensino. In: . Para uma tecnologia educacional. Porto Alegre: Artmed, 1998, p. 257-84.

ARIES, P. História da morte no Ocidente: da Idade Média à atualidade. Rio de Janeiro: Francisco Alves, 1977.

BLACKWELL, B., RODIN, A. E., NAGY, F., REECE, R.D. Humanizing the student-cadaver encounter. Gen. Hosp. Psychiatr., v.1, p.315-21, 1979.

CHARLTON, R., DOVEY, S. M., JONES, J. G., BLUNT, A. Effects of cadaver dissection on the attitudes of medical students. Med. Educ. , v.28, p.290-5, 1994.

FÈDIDA, P. L'anatomie dans la psychanalyse. Nouv. Rev. Psychanal., n.3, p.109-26, 1971.

FOUCAULT, M . O nascimento da clínica. Rio de Janeiro: Forense-Universitária, 1987.

GUSTAVSON, N. The effect of human dissection on first-year students and implications for the doctorpatient relationship. J. Med. Educ., v.63, p.62-4, 1988.

HORNE, D. J., TILLER, W.G., EIZENBERG, N., TASTHEVSKA, M., BIDDLE, N. Reactions of firstyear medical students to their initial encounter with a cadaver in the dissecting room. Acad. Med., v.65, p.645-6, 1990.

KORPI, M. F., CARBONARA, C.P., YOUNG, V.E. The impact of nonlinear editing on post-production process. SMPTE J., n.10, p. 641-46, 1996.

MARKS, S. C., BERTMAN, S. L. Experiences with learning about death and dying in the undergraduate anatomy curriculum. J. Med. Educ., v.55, p.48-52, 1980.

MAUNNONI, M. O nomeável e o inominável. Rio de Janeiro: Zahar, 1995.

PENNEY, J. C. Reactions to human dissection: a report and a proposal for curriculum modification.

Proc. Annu. Conf. Res. Med. Educ. v.22, p. 220-5, 1983.

SOUZA, A. N. A reflexão sobre a impotência: SIDA/AIDS, uma experiência em Psicologia Médica.

Rio de Janeiro, 1988. 388p. Dissertação (Mestrado). Instituto de Psiquiatria, Universidade Federal do Rio de Janeiro.

ZAIDHAFT, S. Morte e formação médica. Rio de Janeiro: Francisco Alves, 1990.

DA NOVA, J.L.L., BEZERRA FILHO, J.J., BASTOS, L.A.M. Lección de Anatomía, Interface _ Comunicação, Saúde, Educação, v.4 , n.6, 2000.

En la formación médica diagnosticamos la crisis del modelo pedagógico/asistencial que se revela, entre otros síntomas, en la ideología de frialdad y distanciamiento por la que atraviesa la práctica médica. Este modelo de relación médico-paciente reproduce la relación estudiante-cadáver. Apuntando a la modificación de tal ideología desarrollamos, en la Universidade Federal do Rio de Janeiro, como actividad transdisciplinaria conjuntamente al curso de Anatomía, grupos de reflexión con alumnos del primer periodo de la Faculdade de Medicina. A partir de los resultados desta experiencia llevada a cabo durante dos años, denominada "El cadáver y la formacción médica", realizamos con el apoyo de la Fundação José Bonifácio, un video didáctico: "Lección de Anatomía", de forma multidisciplinaria con profesores y alumnos del Instituto de Artes e Comunicação Social da Universidade Federal Fluminense, de la Faculdade de medicina de la UFRJ y del Núcleo de Tecnologia Educacional para a Saúde da UFRJ (NUTES). Pretendemos que la utilización de este recurso audiovisual se transforme en una herramienta más para enriquecer la enseñanza y la práctica médica introduciendo la discusión de cuestiones éticas. La investigación y la realización del video nos mostraron la posibilidad de repensar y de innovar la enseñanza universitaria transformándose para todos nosotros en una lección de convivencia democrática.

PALABRAS CLAVE: formación médica, anatomía, video didáctico. 